\title{
Immigrant investor programmes in the European Union (EU)
}

\author{
Jelena Džankić, European University Institute ${ }^{l}$
}

\begin{abstract}
Immigrant investor programmes (IIPs) have mushroomed around the world in recent years. Focusing on the EU context, where each Member State has at least one legal mechanism for granting residence or citizenship rights in exchange for investment, this paper has a twofold objective. First, it seeks to develop a typology of IIPs on the grounds of investment amounts and status obligations. Second, the paper applies this typology to map and examine immigrant investor programmes in the EU. Rather than looking in detail at the politics of investment-based migration in each country, this study identifies general conditions across states that enable different types of IIPs to develop.
\end{abstract}

Keywords: immigrant investor, European Union, citizenship, residence

\section{Introduction}

Immigrant investor programmes (IIPs) are policies developed by countries seeking to attract the wealthy to become their residents or citizens. Historically, some form of an exchange between money and membership can be traced back to Ancient Rome (Džankić 2012). Yet, contemporary investment-based migration has laid its roots in the early 1980s, when the first wave of programmes though which the wealthy could

\footnotetext{
${ }^{1}$ Contact: Jelena Dzankic, Research Fellow, GLOBALCIT Observatory, European University Institute, Via Boccaccio 121, 50014 San Domenico di Fiesole, Italy. Email: jelena.dzankic@eui.eu
} 
obtain new passports or residence cards emerged (GRIR 2016). In 1982, the government of Australia introduced its Business Migration Program (BMP) granting residence rights on the basis of investment (Stevens 2016). Between 1986 and 1993, the United States (US), the United Kingdom (UK), New Zealand, Canada, Uruguay and Panama, amended their immigration policies along the same lines. The Caribbean islands of St. Kitts and Nevis and the Commonwealth of Dominica, and the African volcanic archipelago of Cape Verde developed programs though which investors could obtain passports (GRIR 2016). Other European countries, such as Austria or Ireland, used the state's discretion to naturalize investors on grounds of “associations”, “achievements” or "exceptional contribution” (Džankić 2014; Carrera 2014).

Only a few immigrant investor schemes were set up in the early 2000s, including the Cypriot Naturalisation by Exception Program (2002), the ordinary residence for investors in Greece (2005), and the High Net Worth Residence in Malta (2006). The second wave of wealth-based immigration programs appeared in the aftermath of the 2007-2009 global financial crisis, in island nations off the coast of Africa (Comoros, Mauritius), North America (Turks and Caicos, Antigua and Barbuda, St. Lucia) and in Oceania (Fiji, Vanuatu). It proliferated in the European Union (EU) during the peak of the Eurocrisis. Between 2011 and 2013, a number of European states have launched fresh immigrant investor programmes or revived those they had previously. Bulgaria, France, Hungary, ${ }^{1}$ Ireland, Latvia, Spain, Portugal, and the Netherlands adopted residence by investment programmes. In 2013, Cyprus revised its investor citizenship programme and Malta introduced one. By 2016, each EU Member State has adopted at least one legal mechanism for facilitating investment-based migration, be it through the state's discretion to naturalise, an 
investor citizenship scheme, or a programme granting 'a path to citizenship' via residence rights.

Against such a background, this article has two goals. The first objective is to develop a typology of IIPs, and identify environments conducive to different types of programmes . The second objective is to apply this typology and examine immigrant investor programmes in the EU. As a result of the particular legal and political architecture of the EU, citizenship and residence regimes of the 28 member states are interrelated. These two statuses give rise to different sets of rights across the Union. Hence, programmes offering 'paths to citizenship' via residence rights have target groups and beneficiaries different from those directly offering citizenship to investors. $^{2}$

Unlike in other parts of the world, where investment-based citizenship programmes entitle their beneficiaries to visa-free travel, preferential tax rates, and protection abroad, in the EU, they are associated with an additional bundle of political rights. These rights emanate from the Citizenship of the European Union (EU citizenship), established in 1992 to define the rights of citizens of the member states across the Union. They include the freedom of movement and residence, the right to non-discrimination on grounds of nationality, voting rights in municipal and European Parliament elections, consular protection by another EU country, etc. Importantly, EU Citizenship is additional to and dependent on national citizenship (article 20 of the Treaty on the Functioning of the European Union, TFEU). Hence the investor citizenship programmes in the EU target individuals who will make a single investment in one country's economy, but who are primarily interested in additional opportunities that come from EU citizenship. 
By contrast, residence rights are commonly limited to a single country, with some Union-wide rights arising from the common market. That is, residence in an EU member state does not immediately result in the freedom of movement across the Union or protection abroad. It can have a limited effect on the visa-free travel in the Schengen area (for stays in other member states of up to 90 days within 6 months). Furthermore, residence in the common market countries enhances possibilities for developing business. The free movement of capital implies that all transfers within the EU are treated as domestic and thus do not incur additional costs (Articles 63 to 66 of the TFEU). ${ }^{3}$ Therefore, the target group of programmes that offer residence rights to investors are migrants who will continuously engage in the respective countries' economies through business opportunities of the common market.

In terms of content and structure, this paper does not analyse the detailed politics of investment-based migration, or offer normative arguments for supporting or rejecting it. Rather, it develops a typology of immigrant investor programmes and identifies commonalities of environments in which citizenship and residence statuses are exchanged for money. The paper then applies this approach to study immigrant investor programmes in the EU. The conclusion to the paper clears the grounds for further normative and comparative studies of immigrant investor programmes and briefly discusses their implications beyond the EU context.

The study relies on individually collected data on legal provisions regulating immigrant investor programmes in 28 member states of the EU. Full texts of constitutions and most recent citizenship laws have been accessed through the EUDO Citizenship Observatory’s "National Citizenship Laws Database”. Residence-related legislation has been collected separately through research on each member state's aliens acts and subsidiary legislation. It is supplemented by desk research on political 
and economic environments in countries operating IIPs. As the argument focuses on a comparison of legal provisions, interviews with stakeholders in each country go beyond the scope of this article.

\section{A typology of immigrant investor programmes}

Although the exchange of communal membership for a pecuniary contribution has deep historical roots, until recently, only a few academic sources have focused specifically on it. Rather, there has been some tangential discussion of this issue in the debates over the constitution of the demos, which highlighted the normative tensions inherent in the sale of citizenship (Buchanan 1965; Carens 1987; Walzer 1983). Studies that explored the historical developments of citizenship (Shachar 2000) viewed it as a part of broader trends of inclusion and exclusion. As the number of immigrant investor programmes has increased in recent years, literature on this topic has now grown to a handful of studies. Džankić (2014), Shachar and Hirschl (2014), Shachar and Bauböck (2014), Parker (2016), and Tanasoca (2015) explored the ethical dimensions of the link between citizenship and money highlighting the benefits of and controversies of selling citizenship. Other academics have looked at investment-based citizenship and residence schemes around the world and explored their impact on global inequality (Boatca 2015; Carrera 2014; Christians 2017; Xu et al. 2015;). While Džankić (2012) proposed a general classification of these programmes into 1) discretionary naturalisation on grounds of national interest; 2) investor citizenship; 3) golden residence programmes, a comprehensive typology of these programmes, which would allow broader comparisons, is yet to be developed. 
In general, immigrant investor programmes can be divided into two groups based on the purpose and outcome of policy for the state and for the investor: 1) investment-based residence programs (IRPs), linked to temporary or permanent residence rights; and 2) investment-based citizenship programs (ICPs), providing the applicant with full membership. In both cases, immigrant investor programs result in a legal status (resident or citizen) derived from a particular amount of financial assets the applicant has transferred to the destination country. Hence the typology for classifying immigrant investor programs has two dimensions: investment obligation and status obligation.

Since the purpose of IIPs is to attract foreign capital to the destination country, the investment becomes central to the attribution of status. There are however major discrepancies as to how much investment different programmes require. In their studies, both Džankić (2015) and Parker (2016) noted that financial requirements range from several tens of thousands to ten million euros. Hence on the 'investment obligation' dimension, we can develop a scale of countries requiring: 1) very low investment (below 100,000 euros); 2) low investment (100,0000 euros or more, and below 0.5 million euros); 3) medium investment ( 0.5 million euros or more, but below 1 million euros); 4) high investment ( 1 million euros or more, but below 5 million euros); 5) very high investment (over 5 million euros). In operationalizing this dimension, IIPs are ranked 1 to 5, as above. For example, the Greek programme, requiring an investment of 0.3 million euros will receive the score of 2 , while the UK's Tier 1 (Investor) visa with the required investment of 1 million GBP (1.12 million euros, October 2017) will be at the fourth point of the scale. In countries where a single programme offers multiple options for investment in exchange for one status (e.g. Spain), only the minimum amount will be ranked. This ranking 
mechanism is based on the assumption that the lowest investment is a sufficient for obtaining status under the given programme.

The outcome of all immigrant investor programmes is the conferral of a legal status (citizen or resident) to the investor. Each status is linked to a particular set of rights. Citizens are full members of a polity, whose rights normally include the franchise, social rights and consular protection, and are accompanied by the visa-free travel regime granted by the country's passport. Foreign residents have the right to live or settle in a given country, but their voting rights are limited (usually to the local level). They are also required to undertake further actions aimed at securing the continuation of their resident status or at eventually obtaining citizenship.

In the typology of IIPs, as noted by Parker (2016), it is essential to reflect on the balance between rights and obligations. Therefore, the ranking on the 'status obligation' dimension needs to reflect two key questions: 1) what obligations does the investor have to obtain citizenship rights?; and 2) what obligations does the investor have to maintain residence rights? This allows us to develop a 5-point scale, in which the obligations that an individual has to access and keep their status are ranked from lowest (1) to highest (5). The scale thus runs as follows: 1) citizenship rights obtained with no visit to the country; 2) citizenship rights obtained with registered residence but scarcely any physical presence is required; 3) registration of residence and multiannual continuous physical presence is required, but the programme results in citizenship; ${ }^{4}$ 4) residence rights are maintained by registration, but limited physical presence is required and investors are subject to a special tax status; and 5) residence rights are maintained by registration, and physical presence of over 6 months and all regular taxes are payable. The logic of such a scale is that under the lowest status obligation (1), the investor obtains citizenship almost directly; under the highest one 
(5) he or she is bound by compulsory ordinary residence, which after multiple years might result in citizenship.

Table 1 (below) offers a summary of these two dimensions through a general typology, which discusses some general characteristics of states that adopt a certain type of policies.

[Table 1 near here]

The typology is reliant on the status dimension, because the amount of the investment obligation reflects sizes and particular needs of different economies. Table 1 (above) contracts the 'status obligation' dimension into (1) 'facilitated citizenship' (status obligations 1, 2, 3 on the above scale); (2) 'facilitated residence' (status obligation 4) on the above scale); (3) 'ordinary residence' (status obligation 5 on the above scale).

Programmes that facilitate the acquisition of citizenship alleviate significantly (or completely) the residence requirement in the form of an individual's physical presence in the country. They are based on the idea of the benefits of a single pecuniary contribution, and target wealthy migrants who would not engage in political processes ('long-distance citizens'). Hence in states running such programmes, the one-off investment makes a considerable impact on the economy and therefore such states are likely to be small or economically weak. Programmes that facilitate the acquisition and maintenance of residence rights through limited physical presence target individuals who are on the lookout for business opportunities in the destination country, but are detached from political processes ('long-distance migrants'). Such states are likely to have specific economic needs, which are met through investment rather than human capital. Finally, programmes requiring 
investment and physical presence in exchange for residence rights seek to attract continuous engagement by individuals who are willing to take part in the destination country's political life. States operating such programmes pursue an active and continuous economic contribution by prospective citizens (migrants). In the following sections, we operationalize the programmes in the EU along the five-point scale, and use the typology in Table 1 (above) to subsequently explore which environments are favourable to the development of different kinds of IIPs.

\section{Operationalising and classifying immigrant investor programs in the EU}

The landscape of European immigrant investor programmes reflects a variety of policies. The majority of the EU Member States can use the state's prerogative to constitute its demos and decide on those who have 'earned' to be their nationals. They facilitate naturalisation on the basis of national interest or exceptional contribution to the state. Bauböck and Wallace-Goodman $(2010,7)$ highlighted that this type of naturalisation is not commonly used, and sometimes the number of new citizens is limited by law, e.g., not more than ten people annually in Estonia. ${ }^{5}$ In this context, the state has the discretion to equalize the investment with "national interest", or "exceptional contribution" in the form of services rendered to the state. The data at the European Union Democracy Observatory (EUDO) on Citizenship indicate that out of the 28 Member States of the EU, 22 allow discretionary naturalization on grounds of special achievements, which may include, in addition to the economic interest, the cultural, sports or scientific one. ${ }^{6}$ In only 4 of them, namely Austria, Bulgaria, Slovakia and Slovenia, "economic" or "commercial" interest has been mentioned in 
the nationality law as grounds for facilitated naturalization. In 19 countries of the EU, provisions on naturalisation based on national interest do not explicitly mention economic contribution. Since the conferral of citizenship in such cases is fully discretionary and investment amounts are not specified, these legal provisions are excluded from the analysis.

Rather, the analysis focuses on programmes in four EU Member States Bulgaria, Cyprus, Malta, and Romania where clearly stipulated investment amounts can be assessed against the obligations investors have to meet to obtain citizenship rights. In addition to these four ICPs, the analysis also includes programmes in the EU member states that offer residence rights for investment or entrepreneurial activity. Specific programmes with defined investment amounts and conditions the applicant needs to meet in order to receive and maintain residence rights exist in eighteen countries (Bulgaria, Croatia, Cyprus, the Czech Republic, Estonia, France, Greece, Hungary, Ireland, Latvia, Lithuania, Malta, the Netherlands, Portugal, Romania, Spain and the UK). These are analysed below, unlike the legislative provisions in Belgium, Germany, ${ }^{7}$ Italy Poland, Slovakia and Slovenia, where residency through on investment is facilitated, but the details of the pecuniary contribution or the type of residence are not stipulated in laws.

[Table 2 near here]

Table 2 (above) gives an overview the legislative grounds, investment and status obligations in twenty-seven programmes existing in twenty-three European states, including the six programmes that could not be coded. A total of twenty one programmes have been coded along the lines presented in the previous section, allowing us to map the variety of different approaches to the relationship between 
investment and status obligations. These are best captured in Figure 1 (below) representing a graphic overview of all immigrant investor programmes in the EU.

[Figure 1 near here]

The data visualisation in Figure 1 (above) indicates that the lower left corner is empty (low investment, low status obligation) and that ICPs are located in the upper left third (high investment, low status obligation). This indicates that there are no programmes in EU that enable the conferral of citizenship in exchange for a very low or low investment. Rather, the four investment-based citizenship programmes require for high or very high investment amounts and limited physical presence. The six programmes in the centre offer facilitated residence rights (medium-high investment, medium-high status obligation). Programmes in countries that populate the right third require higher status obligations from investors and mandatory residence. Programmes located in the top offer residence rights in exchange for higher, and those bottom lower, investment amounts.

The following section explores in more details characteristics of countries running immigrant investor programmes. In line with the typology presented in Table 1, it identifies environments conducive to different relationships between investment and status obligations.

\section{Understanding immigrant investor programmes in the $\mathbf{E U}$}

In the EU context, the regulation of free movement for citizens and third country nationals also influences policies geared towards investors. That is, citizenship of each Member State grants rights across the Union (article 20, TFEU), and residence 
rights in each Member State grant rights in that state and some rights (e.g. travel, or free movement for permanent residents) across the Union. The classification in the previous section highlights that ICPs in the EU are an exception rather than a rule, and that countries are more prone to introducing residence-based investor programmes. While the state's discretion in deciding on membership is widely accepted, explicit programmes resulting in the sale of citizenship generate significant contention and high political costs, domestically and internationally (Carrera 2014; Johnston 2015). Residence-based programmes are more broadly accepted as they have the potential to generate multiannual tax revenues (Christians 2017). Nonfacilitated IRPs might also have lower political costs as their beneficiaries need to meet the same naturalisation conditions as ordinary applicants (Džankić 2015).

This raises the question of what environments are conducive to ICPs and IRPs, and what can explain the differences in investment and status obligations among these programmes? To better understand this question, we will look in detail at the typology presented Table 1 and operationalized in Figure 1 (above). This will help us to discern some of the motivations of states in attracting 'long distance citizens', 'long distance migrants', or ordinary migrants through these programmes.

Investment in exchange for citizenship rights: on the lookout for 'long-distance citizens'

Programmes populating the lower right quadrant in Figure 1 (above) offer citizenship rights for a clearly specified amount of investment. In the EU, such investor citizenship exists in the four post-2004 countries - Bulgaria, Cyprus, Malta, and 
Romania. They are different in terms of investment and status obligations, which indicates that the purposes of these programs might as well differ.

Having the highest investment obligation, Cyprus only performs due diligence and criminal record checks on applicants, resulting in a quicker procedure for obtaining citizenship. As of June 2017, this country also requires 'permanent residence', which is applied for concurrently with the citizenship request and is a procedural rather than an actual obligation (Decision of the Council of Ministers dated 19.3.2014; as amended in 2017). Malta, Bulgaria and Romania require lower investment, but have additional status-related conditions, including some form of residence, oath of allegiance, or language knowledge. In Bulgaria and Malta, the residence requirement is much lower than the one for ordinary naturalisation (e.g., one year for investors, ten years for other applicants). Substantial physical presence in the country is usually not required, (Dalli 2015) unlike in Romania, where it is set at four years (Act No. 21/1991 on Romanian citizenship, article 8).

Hence the objective of these programmes in Bulgaria, Cyprus and Malta is different from that in Romania. The first three countries seek to attract one-off investment by wealthy elites who will not migrate to or become involved in the polity. In exchange for their pecuniary contribution, these 'long distance citizens' receive the benefits of EU citizenship, which is 'the main generator of rights in the Union' (Kochenov 2011, 338). By contrast, while eventually resulting in citizenship, the Romanian programme includes a substantial residence condition, and other criteria such as the knowledge of the language, culture and constitution. It thus does not aim at creating 'long-distance citizens' but rather individuals actively involved in the polity. 
Yet, why do these countries pursue different kinds of future citizens and why do they require different investment amounts? Before exploring a range of interrelated factors, one needs to be aware of two caveats. First, the number of beneficiaries of such programmes is limited, due to the high pecuniary obligation. Second, if we assume that possessing the citizenship of one Member State generates rights across the EU, beneficiaries of one ICP are unlikely to be interested in obtaining another country's citizenship by investment. Hence the pool of potential applicants becomes smaller with each granted passport.

Cyprus and Malta are two small Mediterranean islands, Commonwealth members, with high-income and service-based economies. With a GDP per capita of 22,600 USD, Malta requires an investment of 1.15 million euros; and Cyprus with 23,300 USD requires 2.5 million euros minimum investment (World Bank 2017). However, the difference in the required investment amounts in Malta and Cyprus cannot be fully explained only by looking at the amount of GDP per capita. They might also reflect the size of these countries. Given that the population of Cyprus is 847,000 and that of Malta 429,300 (Eurostat 2016), an investment of 2.5 million in Cyprus is likely to have similar economic effects on the GDP per capita as that of 1.15 million in Malta.

Equally, the small size of these countries might indicate that they are more interested in investment than in human capital. The likely reason for this is that in small countries, political balances are delicate. Since electoral outcomes are usually decided by margins of several thousand votes, general naturalisation rules are commonly strict (EUDO Citizenship 2016). They pose a barrier to the formation of large immigrant populations that could affect political outcomes. Naturalisation 
conditions are relaxed for investors because they are likely to be few and detached from political processes.

Bulgaria and Romania are post-communist upper-middle-income industrial economies. Bulgaria whose GDP per capita has been just over 7,000 USD requires the lowest investment amount of 0.53 million euros; Romania with the GDP per capita of 9,000 USD and investment of 1 million euros (World Bank 2017). The two countries are also considerably larger than Malta and Cyprus. Bulgaria has a population of 7.2 million and Romania of 19.86 (Eurostat 2016). Hence investments of these amounts are likely to have smaller impacts on the economies of Bulgaria and Romania than on those of Malta and Cyprus. Bulgaria introduced its ICP in 2013 and Romania in 2009, likely due to the effects of the global financial crisis, which significantly reduced the amounts of foreign direct investment in these countries (World Bank 2017).

Yet unlike Romania, which conditions the conferral of citizenship with a fouryear residence and integration, Bulgaria requires scarce presence of investors on its soil. This might indicate that the primary purpose of the programme in Bulgaria is to re-capitalise the country's economy, while that in Romania might be related to attracting human capital. Engagement in the polity does not feature as an explanatory factor for the absence of the status obligation in Bulgaria and its existence in Romania. Given the large size of these countries, and the low number of investor citizens, ICP beneficiaries are unlikely to significantly affect political and electoral outcomes.

In sum, both small and large countries might seek to attract 'long-distance citizens', but the investment needs to have an effect on the country's GDP. In small countries, further common elements of environments conducive to these programmes include geographical isolation (island states), Commonwealth membership, and 
service-oriented high-income economies. In large countries, such common elements would include middle-income economies based on industry, as well as the experience of transitioning from communism to capitalism. While the sample of four countries in the EU is not conducive to major generalisations, research (Džankić 2012; GRIR 2016) has indicated that indeed, ICPs emerge mostly in small island states, such as Antigua and Barbuda, Comoros, the Commonwealth of Dominica, Saint Kitts and Nevis, Vanuatu, etc.

Investment in exchange for facilitated residence rights: attracting 'long-distance migrants,

Figure 1 (above) indicates that Cyprus, Greece, ${ }^{8}$ Malta, Ireland, Spain and Portugal offer facilitated residence rights in exchange for a pecuniary contribution directed towards a specific sector. Neither of these countries requires investors to be physically present on their soil for extended periods of time and they all facilitate tax obligations for non-habitual residents. In regards to the latter, Christians $(2017,3)$ notes that 'governments increasingly appear to view their tax systems as a means of potentially increasing the value of residence and citizenship in their countries'. In this sense, states operating these programmes compete for 'long distance migrants' who are fiscal residents, not actively engaged in the polity.

Cyprus offers facilitated permanent residence to investors, conditioned with one visit to the country. The programme is linked to the country's favourable tax climate, whereby non-domiciled residents pay a progressive tax on their worldwide 
income, but are exempt from domestic taxes such as the defence contribution (17 per cent) and tax on passive interest income (30 per cent) (Kälin 2016).

Greece, Malta, Ireland, Portugal and Spain offer temporary residence permits, with little obligation of physical presence. ${ }^{9}$ In Greece, Malta, Ireland and Spain, the applicant is required to prove that they have travelled to these countries or visited them during the validity of their residence permit. In Portugal, for residence permit renewal purposes, applicants may be asked to deliver evidence that they have resided in the country for 7 days in the first year and 14 days in the subsequent two year periods (article 5, Order n. 1661-A/2013). In addition to relaxing the physical residence requirement, Greece, Ireland, Malta, Spain and Portugal also have a facilitated tax regime for investors, who are considered non-habitual residents. These countries differentiate between 'residence' and 'tax residence', whereby only those present on the country's soil for over 183 days are subject to the regular tax regime. For instance, holders of Malta's residence permit but who are not physically present in the country for more than 183 days are taxed for Malta-based capital gains and on a remittance basis for foreign income. In a similar fashion, since 2015 Spain allows investors to become non-habitual residents subject to a $19 \%$ tax on Spain-based income as of 1 January 2016. This policy option has been influenced by Portugal, where investors benefit from a non-habitual resident tax status, with a $20 \%$ tax $(3.5 \%$ surcharge as of 2015) on Portugal-based income. Ireland taxes non-habitual residents only for Ireland-based income and has a corporate tax rate of $12.5 \%$ (Deloitte 2017). In Greece, non-habitual residents are taxed for their Greece-based income starting at 22\% (Deloitte 2017).

Spain and Portugal offer investors the possibility for naturalisation after ten and six years of such facilitated residence, respectively. Ireland grants only residence 
rights to investors through this programme, but physical presence is required for naturalisation. In Greece, the permit obtained through investment grants facilitated residence rights, but this residence does not count towards citizenship or EU longterm resident status (Law 4251 on Immigration and Social Integration Code and other provisions, article 20). In all of these countries, third country nationals who are not investors can lose their residence rights if they are absent from the country for substantial periods of time (usually six months).

The common characteristic of environments in which such programmes emerge is that, with the exception of Cyprus and Malta, they are medium-sized economies in which particular sectors (e.g., real estate) have been particularly affected by the financial crisis and the subsequent European debt crisis (Parker 2016). These programmes do not target migrants, but rather individuals who will contribute to the fiscal system through taxes or to the vulnerable aspects of the country's economy. In Cyprus and Malta, where these programmes can be integrated in citizenship by investment schemes, the key objective is to attract a one-off or shortterm influx of capital. In other countries, a continuous and maintained financial investment on behalf of the applicant is required for maintaining residence rights and eventually obtaining citizenship.

Investment in exchange for ordinary residence rights: attracting wealth and participation 
The top two quadrants in Figure 1 (above) are reserved for countries that exchange residence rights for investment. The upper part of both left and right quadrants indicate that countries seek migrants, who will also be participants and stakeholders in their destination countries. A total of 11 countries (Bulgaria, Croatia, Czech Republic, Estonia, France, Greece, Latvia, Lithuania, the Netherlands, Romania and the UK) currently offer residence rights for clearly stipulated investment amounts. Their IRPs enable applicants obtain temporary but renewable residence permits, which would subsequently set them on the track to permanent residence or citizenship.

In addition to these programmes, Hungary used to offer permanent residence until 31 March 2017. The Hungarian IRP has been suspended due to controversies over its transparency (Nagy 2016). Under the Hungarian programme, an investment of 300,000 euros (originally 250,000 euros) qualified investors for a settlement visa, which enables foreign nationals to stay in Hungary for an indefinite period of time and spend 3 out of six months in other Schengen countries. ${ }^{10}$ The grounds for the programme were adopted in 2007, during the rule of the Hungarian Socialist Party. In 2012, detailed IRP rules were proposed by Fidesz - Hungarian Civic Alliance, primarily as a mechanism of regulating the status of Chinese nationals investing in the country. Antal Rogán, one of the Fidesz parliamentarians who proposed the bill, corroborated that while the IRP could be used for settlement of all foreigners, it originated in negotiations with China through the Chinese-Hungarian Friendship Association (Hungarian Parliament 2012, 284-332). The combination of Chinese single citizenship policy and the lobbying of commercial law firms led to Hungary's preference of a permanent IRP, rather than temporary permit or citizenship by investment (EMN Focused Study 2014, 8). While suspended at present, programme might reopen in 2018, subject to approval of the country's Parliament. 
Other EU Member States run temporary IRPs with high status obligations, whereby to maintain residence rights investors are bound to be present on the countries' soil. However, the pecuniary contribution in temporary IRPs ranges from 65,000 euros in Estonia to 10 million euros in France. Even so, we can observe several trends regarding the investment amounts. First, post-communist countries generally require lower pecuniary contributions. Croatia, Czech Republic, Estonia, Latvia, Lithuania and Romania grant residence rights in exchange for investments below 100,000 euros, while Bulgaria requires the minimum investment of 127,000 euros. GDPs per capita of these countries are all below 18,000 USD (World Bank 2017). Second, France, the Netherlands and the UK, which are large EU economies with GDPs per capita over 36,000 USD (World Bank 2017), require significantly higher investment amounts. These range from 1.17 million euros ( 1 million GBP) in the UK, to 1.25 million in the Netherlands, to 10 million in France.

This division indicates that countries offering ordinary residence in exchange for investment are on the lookout for migrants who will also be active participants in the polity. In all of these countries, the physical residence requirement is meant to create a link between the investor and the destination country, not the least by paying taxes, but also through socialising. The different investment amounts reflect the sizes and conditions of individual European economies - with major economies requiring multi-million, multi-annual investments; and minor, post-2004 economies, and the severely crisis-struck Greece, require comparatively lower investment, or investment directed to an underdeveloped sector (e.g. technology in Bulgaria). 


\section{Conclusion}

In exploring contemporary migration, it is important to consider the development of policies targeting population linked to transnational, supranational and subnational political spaces. Immigrant investor programs are one of the lenses that can provide a fresh look on the questions of membership in the contemporary world. These programmes are different from other immigration policies, because they target a limited number of beneficiaries. Immigrant investor programs seek to attract the beneficiary (or his or her capital) to the state as opposed to many other immigration policies, which restrict the conditions of entry and stay of immigrants (e.g., family reunification, refugees)

The purpose of this paper was to classify the immigrant investor programs on grounds of the relationship between the required investment and status obligations. While there are commonly a number of conditions an individual needs to meet in order to become a citizen of a given country, the residence criterion is the most important one and has been used as a proxy for the typology. The reason for this is that by mandatory residence, an individual is likely to integrate in the country, learn the language, establish social ties, and make it the nexus of his or her life. Hence by taking into account the dimensions of investment and status, the typology developed in this paper helps to understand what kind of citizens or residents states seek to attract. Programmes requiring higher investment amounts and little to none physical presence have as their objective a short-term inflow of funds and 'long-distance citizens'. Similarly, programmes that facilitate residence rights in exchange for investment target 'long-distance migrants' who will contribute to their economy without engaging in political processes. They differ from programmes that exchange 
ordinary residence rights for investment, which target migrants who will offer a continuous input in the respective country's economy and politics.

The immigrant investor programs in the EU are exemplary of these dynamics, especially in the context of the freedom of movement in the EU and the rights of EU citizenship. The analysis in this paper reveals that while Bulgaria, Cyprus, Malta and Romania all run ICPs, the first three countries have scarcely any residence requirement while Romania requires four years. This indicates that programmes in Bulgaria, Cyprus and Malta target investment, as opposed to Romania, which also pursues human capital. Additionally, programmes in five countries offer the possibility for investors to obtain residence rights without extensive physical presence. Analysis indicates that this quest for 'long-distance migrants' is likely to be caused by acute economic needs of these countries, most of which have been adversely affected by the economic crisis. Finally, programmes in 11 EU countries offer residence rights to investors, but require them to be physically present on their soil for over 6 months per year. The goal of these programmes is to attract engaged entrepreneurial migrants rather than a single inflow of funds.

In conclusion, this paper has offered a general a typology of immigrant investor programs, and applied it to the case of the EU member states. It is expected that this typology will facilitate further normative and comparative studies of investment-based migration. Given the salience of this topic and the increasing number of investor citizenship programmes worldwide, a major avenue is opened in citizenship and immigration studies to examine the instrumental uses of membership statuses, as well as strategies that direct and indirect beneficiaries pursue through immigrant investor programmes. 
${ }^{1}$ The Hungarian Investment Immigration Program was indefinitely put on hold on 31 March 2017. However, it is included in this analysis as it has been developed in the second wave of contemporary IIPs in the EU. Subject to parliamentary approval, the programme might reopen in 2018.

${ }^{2}$ In both cases, beneficiaries will include almost exclusively third country nationals (TCNs), as EU citizens and permanent residents already enjoy free movement rights.

${ }^{3}$ The only exception to this rule is currently Greece, in which capital controls are in place.

${ }^{4}$ This type of programmes is very rare, nonetheless existent in some countries such as Romania. It has been ranked on the third point of the scale since the acquisition of citizenship is facilitated. Even though residence is mandatory, it is lower than in cases of ordinary naturalisation. In the fourth point of the scale, residence is facilitated but the number of years for naturalisation is unchanged.

${ }^{5}$ Eurostat (2015) and national statistical offices of the EU's Member States provide no information on the exact numbers of discretionary naturalisation broken down by grounds for admission.

${ }^{6}$ The citizenship laws of the Denmark, Finland, Poland, Spain, Sweden and the United Kingdom do not contain provisions on naturalisation on grounds of special achievements. EUDO CITIZENSHIP (2016). Global Database on Modes of Acquisition of Citizenship. San Domenico di Fiesole: European University Institute. Available at: http://eudo-citizenship.eu/global-modes-of-acquisition. See information under "Mode A24, Special Achievements".

${ }^{7}$ Until August 2012, Germany offered an investor residence scheme to applicants who invested 250,000 euros and created 10 jobs. Amendments to article 21 of the German Residence Act abolished the minimum thresholds for investment, but retained an entrepreneurial program, granting a higher discretion to the authorities to decide on the economic priorities of the state.

${ }^{8}$ The 2005 programme offered ordinary residence rights in Greece, while the 2014 offers facilitated residence with minimum requirements of physical presence.

${ }^{9}$ The original programme adopted by Spain required beneficiaries of the programme to be physically present in the country for over six months. The 2015 amendments, aimed at making the Spanish programme compared to the Portuguese one abolished this requirement.

${ }^{10}$ After five years of continuous and legal residence with this permit, investors are entitled to apply for an EU Long Term Residence (LTR), provided that they are not absent Hungary for six consecutive months (and less than ten months in the five-year period). This entitles them to EU-wide rights, including free movement of workers and social benefits (Council Directive 2003/109/EC). 


\section{Reference list}

Act No. 21/1991 on Romanian citizenship. Official Journal of Romania, Part I, No. 576/13 [Romania].

Bauböck, Rainer and Sarah Wallace-Goodman. 2010. "Naturalisation. EUDO citizenship policy brief No. 2." EUDO Observatory. Available at «http://eudo-citizenship.eu/docs/policy brief_naturalisation.pdf»

Boatcă, Manuela. 2015. Global inequalities beyond Occidentalism. London: Ashgate.

Carrera, Sergio. (2014) "How much does EU citizenship cost. The Maltese citizenship-for sale affair: A breakthrough for sincere cooperation in citizenship of the union." CEPS Policy Paper. Available at «http://papers.ssrn.com/sol3/papers.cfm?abstract id=2430117»

Christians, Allison. (2017) "Buying in: Residence and Citizenship by Investment”. St. Louis University Law Journal, Forthcoming. Available at SSRN: https://ssrn.com/abstract $=3043325$

Consolidated Version of the Treaty on the Functioning of the European Union (2008) Official Journal of the European Union C 115/47.

Dalli, Miriam. 2015. 'IIP regulator confirms 'physical presence' not required for golden passport." Malta Today, 28 October. Available at «http://www.maltatoday.com.mt/news/national/58694/iip_regulator_confirms physical presence not required for golden passport\#.VoO3XxGe5g0»

Deloitte (2017). Taxation and Investment in Ireland 2017. Available at: «https://www2.deloitte.com/content/dam/Deloitte/global/Documents/Tax/dttltax-irelandguide-2017.pdf » 
Dumbrava, Costica. 2014 Nationality, citizenship and ethno-cultural belonging: preferential membership policies in Europe. London: Springer.

Džankić, Jelena. 2012. "Ius pecuniae: investor citizenship in comparative perspective." EUDO/RSCAS Working Paper 14/2012. Florence: EUI.

Džankić, Jelena. 2015. "Investment-based citizenship and residence programmes in the EU.” EUDO/RSCAS Working Paper 2015/08. Florence: EUI.

EMN Focused Study. 2014. Admitting Third-Country Nationals for Business Purposes: Hungary. Available at «http://ec.europa.eu/dgs/home-affairs/whatwe-do/networks/european_migration_network/reports/docs/emnstudies/13a.hungary_business_study_en_version.pdf»»

EUDO CITIZENSHIP. 2016. Global Database on Modes of Acquisition of Citizenship. Available at «http://eudo-citizenship.eu/global-modes-ofacquisition»

Eurostat. 2015. "EU population up to 508.2 million at 1 January 2015." Eurostat News Release. Available at «http://ec.europa.eu/eurostat/documents/2995521/6903510/3-10072015-APEN.pdf/d2bfb01f-6ac5-4775-8a7e-7b104c1146d0»

GRC. 2016. Global Residence \& Citizenship Report 2016. Available at «http://globalresidenceindex.com/wp-content/uploads/2015/12/GRC-Report2016.pdf»

GRIR. 2016. Global Residence Industry Report. Available at «http://globalresidenceindex.com/wp-content/uploads/2016/05/GRIR_16.pdf»

Hansen, Randall. 2002. "Globalization, Embedded Realism, and Path Dependence". Comparative Political Studies 35: 259-283. 
Hidalgo, Javier. 2015. “Selling Citizenship: A Defence.” Journal of Applied Philosophy, DOI: 10.1111/japp.12117.

Hungarian Parliament. 2012. Speech of Antal Rogán, Parliamentary Meeting Day No. 231, 29 October. Available at «http://www.parlament.hu/web/kulturalisbizottsag/a-bizottsagulesei?p_auth=FdZfvw6p\&p_p_id=pairproxy_WAR_pairproxyportlet_INSTA $\underline{\text { NCE_9xd2Wc9jP4z8\&p_p_lifecycle }=1 \& p \_p \_s t a t e=\text { normal\&p_p_mode }=v i e w}$ \&p_p_col_id=column$1 \& p \_$_ col_count $=1 \&$ pairproxy WAR pairproxyportlet_INSTANCE 9xd2 Wc9jP4z8 pairAction=\%2Finternet $\% 2$ Fcplsql\%2Fogy naplo.naplo fadat akt us $\% 3 F p \_c k 1 \% 3 D 39 \% 26 p \_u l n \% 3 D 231 \% 26 p \_f e l s z \% 3 D 284 \% 26 p \_f e l s z i g \% 3 D$ 332\%26p_aktus\%3D61»

Kälin, Christian. 2016 Global Residence and Citizenship Handbook. Zurich/London/Hong Kong/New York: Ideos.

Kochenov, Dimitry. 2011. "Double nationality in the EU: an argument for tolerance". European Law Journal 17 (3): 323-343.

Law 4251 on Immigration and Social Integration Code and other provisions.

Government Gazette of the Hellenic Republic No. 80, April 2014 [Greece].

Nagy, Boldizsár (2016). In Whose Interest? Shadows over the Hungarian Residency Bond Program. Geneva: IMC and TI. Available at: https://transparency.hu/wp-content/uploads/2017/01/In-WhoseInterest_Shadows-over-the-Hungarian-Residency-Bond-Program.pdf

Order n. 1661-A/2013 of the Ministry of Foreign Affairs and of the Ministry of Internal Affairs [Portugal]. 
Parker, Owen. 2016. "Commercializing Citizenship in Crisis EU: The case of Immigrant Investor Programmes." Journal of Common Market Studies, doi: 10.1111/jcms.12462.

Shachar, Ayelet and Rainer Bauböck (eds). 2014. Should Citizenship be for Sale? EUDO/RSCAS Working Paper 01/2014. Florence: EUI.

Shachar, Ayelet and Ron Hirschl. 2014. "On Citizenship, States, and Markets." Journal of Political Philosophy 22: 231-257.

Spiro, PeterJ. 2012. "The End of Olympic Nationality”. In Allegiance and Identity in a Globalised World, ed by Kim Rubenstein et al., 478-497. Cambridge: CUP.

Stevens, Rachel. 2016. Immigration Policy from 1970 to the Present. London: Routledge.

Tanasoca, Ana. 2016. “Citizenship for Sale: Neomedieval, not Just Neoliberal?”. European Journal of Sociology 57(1):169-195.

World Bank. 2017. World Bank Open Data: GDP per capita. Available at: http://data.worldbank.org

Xu, Xin, Ahmed El-Ashram and Judith Gold. 2015. “Too Much of a Good Thing? Prudent Management of Inflows under Economic Citizenship Programmes.” IMF Working Paper 15/93. Available at «https://www.imf.org/external/pubs/ft/wp/2015/wp1593.pdf» 